\title{
4 The work of Herbert Simon on Artificial Intelligence
}

Much of what I have found to say in this book came about from my recent introduction by Richard Young into the life and work of Herbert A. Simon. Especially, what I have to say arises from my questioning some of Simon's presumptions about cognition that I found in reading Simon's two books: Administrative behavior: A study of decision making processes in administrative organizations and The Sciences of the artificial. Each book deals with the limits of rationality and about the problems of dealing with complexity. It is his emphasis on the differences between the conceptions of human artifice and sufficing, and his work on the different modes of human problem solving, especially in using artificial intelligence (AI) that fascinates me most. Much of what I want to say is an assimilation of his discussion and a reaction to what Simon said in the two fore mentioned books. Much of my argument against what Simon says consists of undermining his realistic presumptions behind the use of computer models that pervade his writings. In a way I am just playing another game of 'Simon Says'.

Let me provide an introductory illustration of my Simon game by using an isolated quote from Simon:

Rationality implies a complete and unattainable knowledge of the exact consequences of each choice. In actuality, the human being never has more than a fragmentary knowledge of the conditions surrounding his action, nor more than a slight insight into the regularities and laws that would permit him to induce future consequences from knowledge of present circumstances [emphasis added]. (1994: 94)

Let me identify the presumptions that I find behind these italicized terms that I have indicated that lead to his prescriptions that I wish to challenge. How does rationality imply (suggest) (presuppose) knowledge of the exact consequences of choice? The second questionable presumption lies behind his talk of regularities and laws. The term laws, especially the term natural law presupposes a fixity to what happens that is always open to question. Law and nature are loaded terms in discussing questions about knowledge and the ends and purposes of the sciences.

And finally, I interpret Simon's term 'induce' to be used in an unorthodox or in an extraordinary way of speaking and to actually mean by it 'deduce', that is 'It logically allows us to infer.' Simon seems to be supposing in this case that rationality requires a reality of complete and fixed certainties that no one can by their limited nature cognitively attain. These presumptions I want to argue are inconsistent with his notions of artifice and suffice. The term artifice implies in its usage artificial constructions of novel structures and the creation of novel organizations by engineering and planning. But such products of novel design are in the last analysis understood in our ordinary ways of speaking for the most part as meaning emergent 
and novel creations. We find that creative design is about non regulative and unlike law happenings or events, which we through artifice want to create or generate as novel facts. Artifice as a term thus is a correlative of the term creativity. It is in the contrast in the use of these two terms creativity and artifice that we discover the antinomies created by their contrasting uses.

Contrary to Simon's presumption there is still another kind of ignorance I want to contend that frames our existential situation. There is a past that we are oblivious to, and there is a future too about which we are likewise oblivious. We have no adequate concept of the fate (Kismet) of ourselves and the universe. It is in a way a form of folly to predict anything without an adequate concept of what is being predicted. There is ignorance in the folly of trying to explain everything, especially as we can have no conception of what constitutes 'everything'. TOES, fail to predict why and what is living and emerging. The creative artifice of life is not something that is predictable or subject to preconceived designs as to why it occurs.

It is this sort of complexity and change coming from human artifice and invention, especially from those computer programs developed in Artificial Intelligence that appear so creative that continue to befuddle us. AI in developing innovative models and frames for use in the everyday life of business, academic research, and for the organization of the political world, as Simon says, should be tested to be shown to be applicable or proved (empirically verifiable) to be successful. Artifice in AI is more than the randomized uses of mathematical or logical algorithms. It is innovative change that makes optimal conceptions or completely logical rational predictions of the certainty of optimal possible worlds quite impossible.

We have no conception of the scope or scale of what goes on in the actual world especially about the risks that are taken in it by all too many people at the present time in the high tech world. They in the developing forms of expertise are doing so many things differently, and these things are sometimes as we later find even detrimental to our culture. They now are using different models and programs to create and to produce poisons, pathogens, biogenic toxic modifications, and destructive mechanisms especially nuclear weapons that potentially are in the process of destroying the planet and making it unfit for life.

However, ignorance of what we have forgotten and ignorance of things we have experienced does have an object that helps us define in one sense what it is to be ignorant. That sort of ignorance is simply an ignorance of facts that have happened. But when we speak of ignorance we need to be aware that the term has different senses, especially when ignorance turns out to be about things that no one knows about, and especially about what no one can even talk about. It is this sort of ignorance about what we can never know that raises the paradoxes of talking about things that are indefinable. And much of what happens in the world is often indefinable.

What are the boundaries by which we can verbally distinguish these difference degrees and senses of ignorance? How are these senses of 'ignorance' related, that is, if they are related? In speaking of ignorance there is a lack of awareness of the 
immense complications that we find in attending to so much. There is ignorance of the shifting and changing detail that we find in our lives or in our personal worlds. But there is an all-important sense to the term ignorance in that we are ignorant by the limited means we have in communications where we lack all possibility of definition of the terms in the languages we speak.

There can be no definition of what we cannot presently know about especially those things yet to be created. To define what we create would be to create that something before we have created it. There too also is ignorance that has no self-awareness. When we try to escape such possible subjective ignorance by communicating with others, we find that there is also ignorance in those persons with whom we communicate, which helps us know something about them and the world. Sometimes this fact can be easily demonstrated. We thus are bounded by others with their own personal deficits that sometimes constrain us in finding out what we don't know and what it is that we think we too are ignorant about. Ignorance is equally in a way the existential fate of us all. In an ideal way to be human is to try in various ways to eliminate it. It is hoped for in both science and philosophy to eliminate mysteries about ourselves and about the world we live in.

There have been empirical confirmed limitations discovered by psychologists about the brevity of our memories in what we learn and what we have to forget. But some of these limits we know can be transcended by the developments of new schemes and mnemonic devices that create external resources or prosthetics to help us remember. These devices help us simplify and clarify things that we might be able eventually to understand. And they help us do things that we are able to do better and more efficiently and productively in doing things we want to do.

To acquire such knowledge our civilization depends on the external memory of written languages, and especially now on visual representations using graphic and mathematical languages that aid us in escaping some of these psychological limits and deficiencies that limit our knowledge and mastery of events. We are able in the way we communicate with each other to explore the ignorance of others and are able to find why they are ignorant, and in doing so we are able to find in our own little abyss what we too are ignorant about. These explorations and mutual clarifications about what we do and say to each other are limited and constrained by our language use and the various ways of we have of displaying to others the implications of what we say and what we visually display so as to communicate better with others. It is in this sort of context that the politics of language use and usage comes into play.

Let me at this point suggest a distinction to be made between oral and graphic language where by graphic language I would mean written or printed language. Such an assimilation of the visual makes both literature and our scripted expository prose just variants of graphic artifacts. But graphic language then is not simply just the printed word. It includes drawings, pictures, maps, charts, and graphs. It includes the drawings of geometry as well as the formal scripted languages of symbolic logic and mathematics. I wish to use this distinction between oral and graphic language later 
to show just how and why our interpretations of what people are saying in oral and written language is open to different questions about the interpretation of both our and their usage.

Usages I maintain are socially and politically constructed. Likewise, I have defined technical usages of language as standardized professional social constructions of graphic usage. There is a social politics that creates not only technical vocabulary but also devises formal mathematical and logical representations and that equally defines the rules and modes of construction in using schematic visual frames.

There is thus a social form of politics for expertise, for the professions, and for the sciences and disciplines that rank and structure the way we define our ways of dealing with the practical matters of the world. This politics is not only a quest to eliminate misinformation but also a quest for power and the achievement of accepted values. Not only is there then a politics that standardizes our spoken and written languages, there is a social politics to all our graphic languages, especially our formal logical and mathematical languages. And it is this social politics that guides the use and usage that is at the heart of our understanding of the aims and modes of rhetorical action that tries to reach mutual understandings in communication. 